\title{
Substance Abuse as Perceived by Adolescents: A Preventive Approach for Their Safety
}

\author{
Samia A. EL Nagar ${ }^{1,3}$, Warda El shahat Hamed ${ }^{2,3, *}$ \\ ${ }^{1}$ Paediatric Nursing, El-Menoufya University, Egypt \\ ${ }^{2}$ Psychiatric and Mental Health Nursing, Mansoura University, Egypt \\ ${ }^{3}$ Jazan University, KSA \\ *Corresponding author: hanantharwat2005@yahoo.com
}

\begin{abstract}
Substance abuse may lead to criminal behaviors. Substance abuse has major impact on individuals, families and communities, as its effects are cumulative, contributing to costely, social, physical and mental health problems. Aim of the study: This study aims to examine effect of health and psycho education on the adolescents' knowledge, attitude and perception regarding substance abuse. Design: A quasi experimental design was used to conduct this study. Tool of data collection: Data collection was carried out by using the following tools: An interview questionnaire form that covers two parts. Part I: Demographic characteristics such as: age, father and mother's education, parents' job etc... Part II: It comprised 54 items: four items sought information about respondents' level of knowledge and awareness of, and personal familiarity with, illegal drugs; 35 items explored perceptions, attitudes and beliefs about drug use, drug users and drug-related issues plus 15 items elicited socio-demographic data including the respondents' age, marital status etc. Results: There is statistically significant improvement in the level of knowledge after intervention, with $\mathrm{p}=0.000$. Adolescents positive attitude toward addicts has increased post intervention representing $45.8 \%$ of the sample compared with $32.6 \%$ pre intervention. Moreover, the positive perception of the adolescents regarding addiction has increased representing $28.3 \%$ post intervention compared to $3.3 \%$ pre intervention. Conclusion: Adolescents have poor knowledge, poor attitude and poor perception regarding substance abuse. Intervention including health and psychoeducation has an effective result on students knowledge, attitude, and perceptrion of substance abuse. Recommendations: Frequent assessments of adolescents knowledge, attitude and perception regarding substance abuse. Assessing sources of students information and providing frequent educational program for adolecents regarding substance abuse among Egyptian schools. Collaboration of Ministry of Health with Ministry of Information in providing intervention programs targeting adolescents and school students for prevention of substance abuse.
\end{abstract}

Keywords: substance abuse, adolescents, preventive approach, psycho education

Cite This Article: Samia A. EL Nagar, and Warda El shahat Hamed, "Substance Abuse as Perceived by Adolescents: A Preventive Approach for Their Safety.” American Journal of Nursing Research, vol. 6, no. 5 (2018): 299-308. doi: 10.12691/ajnr-6-5-12.

\section{Introduction}

Adolescence is a critical stage in the life-course and can be considered the most transformative period in the individual's life. Substance use is a public health problem among teenagers and young adults. Identifying risk and protective factors from the perceptions of adolescents can help setting up effective, culturally sensitive strategies for primary prevention of substance use [1]. The World Health Organization (WHO) defines substance abuse as harmful or dangerous use of psychoactive substances, including alcohol and illicit drugs. Substance abuse is a public health care problem with global dimension [2].

Widely differing definitions of drug abuse are used in public health, medical and criminal justice contexts. In some cases criminal or anti-social behavior occurs when the person is under the influence of a drug, and long term personality changes in individuals may occur as well. In addition to possible physical, social, and psychological harm, use of some drugs may also lead to criminal behaviors. Substance abuse has major impact on individuals, families and communities, as its affects are cumulative, contributing to costly, social, physical and mental health problems [1,3].

Leitner et al. (1993), in their study of the drug-related views and habits of the general public in Britain, found that those substances cited by respondents as being most harmful were those which had been the focus of greatest political and media attention, namely heroin, cocaine, crack and solvents. Drugs such as cannabis were generally regarded as less harmful than other drugs including opiates, barbiturates, tranquillizers, and 'pills', and opiates were perceived as the most harmful [4]. Drug use can be part of a pattern of risky behavior including unsafe sex, driving while intoxicated or other hazardou, unsupervised activities and in cases when a teen does develop a pattern of repeated use, it can pose serious social and health risks including school failure, impaired memory, problem with family and other relationships, loss of interest in normal 
healthy activities and risk of contracting infectious diseases like HIV or hepatitis $\mathrm{C}$ and mental health problems [3].

Attitude is the belief that represents a psychological state or feeling which disposes the individual to react or respond in a positive or negative manner towards the object, situation or individual under consideration [5]. In many countries substance use is perceived as a moral problem contributing to family shame and loss of prestige. Adolescent perception of drug abuse varies and correlates with the dominant cultural norms. Adolescents who perceived a strong parental disapproval of drug use were less likely to abuse drugs. In addition, participation in religious services correlated with less incidence of drug abuse among adolescents [2].

Emotional problems and substance abuse are causes for dishonor. For adolescents, substance use is a form of emotional coping to manage stressors. It is a way to handle the situation and create balance in their life. A study conducted for incarcerated youth found that anger expression and avoidant coping was concurrent to substance use. In addition to that, adolescents who undergo a traumatic event are more likely to engage in substance use. It is a self-medicated way to avoid the stress and memories of the event [5].

The literature surveyed indicates that knowledge of drugs and perceptions of drug prevalence and the harm associated with drug use tend to be mediated by individual experience of drugs, personal acquaintance with drug users, media coverage of drugs and drug use, and social and demographic variables. Attitudes to drugs and drug use may also depend to some extent on social group membership and the attitudes held by the social group as a whole [6].

Some of the literature on drug misuse suggests that negative societal reaction towards drug users may be influenced to some extent by antidrug media campaigns which typify drug users as generally helpless and dysfunctional addicts who engage in immoral acts. Among the human groups of greatest vulnerability for access to the use of psychoactive substances are children and adolescents $[7,8]$.

Drug abuse prevention is a process that attempts to prevent the onset of substance use or limit the development of problem associated wiyh using psychoactives substances. preventive efforts may focus on the individual and their family or their surroundings. Prevention programs aim to educate childrens and adolescents about the harms of substance abuse, allow students to be interactive and learn skills such as how to refuse drugs. Also, teaching youth and adolescents skills that increase their resistance skills in social situations may increase protective factors in the population. Through careful assessment, identification of substance abuse risk factors, and promoting the enhancement of protective factors of students, both in and out of the school setting, the school nurse can play a vital role in the prevention of substance abuse [8].

\subsection{Importance of the Study}

In Egypt, Substance use and abuse have higher lifetime prevalence among young and middle aged males, less educated persons, working in technical or commercial jobs, with failed marriage, and living in urban areas. Globally, it is estimated that in 2012, between 162 million and 324 million people, corresponding to between 3.5 percent and 7.0 percent of the world population aged 15-64, had used an illicit drug - mainly a substance belonging to the cannabis, opioid, cocaine or amphetamine-type stimulants group - at least once in the previous year [9].

Egypt's National Council for Battling Addiction was reported in 2013, the percentage of drug users over the age of 15 had risen from 6.4 to 30 percent since 2011, with many users opting for the more accessible drug Tramadol. According to Caritas Egypt, in 2011 Tramadol had the second highest percentage of drug users (36.9 percent) with the highest percentage of users (38.5 percent) claiming they were addicted to more than one type of drug [9]. Hence it is a must to make a program for enhancing the knowledge, perception and attitude of the adolescents toward substance abuse to prevent the prevalence of abuse among them.

\subsection{Aim of the Study}

This study aims to examine effect of health and psycho education on the adolescents' knowledge, attitude and perception regarding substance abuse, this achived through:

1. Assessment of adolescents' knowledge, attitude and perception pre intervention.

2. Designing and implementing intervention program consisting of health and psychoeducation.

3. Evaluating of adolescents' knowledge, attitude and perception post intervention .

\section{Methodology}

\subsection{Design}

A quasi experimental design was used to conduct this study.

\subsection{Setting}

The study was conducted at Talkha technical secondary schools in Talkha city, Dakahlia governorate, Egypt.

\subsection{Sampling}

A multistage cluster random sampling was used to select a sample of 240 school students. Talka city contain 1 agriculture secondary school with 200 male students in first grade, one commercial secondary school with 108 male students in first grade. In a total of 2 schools and 240 male students, who agreed to complete the research and stayed until finishing the research. 30 students who included in the pilot study were deleted from the final sample size.

They having the following inclusion criteria: registered in the first grade, their age from 16- 17 and willing to participate in the study.

\subsection{Tools for Data Collection}

Data collection was carried out by using the following tools: An interview questionnaire form that covers two parts: 
Part I: Demographic characteristics such as: residence, brothers number, sisters number, birth orders, father and mothers' education, parents' job and condition [12,13].

Part II: It is adopted from tool of Bryan, et al., (2000) which comprised 54 items: four items sought information about respondents' level of knowledge and awareness of, and personal familiarity with, illegal drugs; 35 items explored perceptions, attitudes and beliefs about drug use, drug users and drug-related issues; plus 15 items elicited socio-demographic data including the respondents' age, gender, marital status, level of education, area of residence, and employment status [9].

The modified tool consists of three parts:

Part A: measures knowledge of the adolescents about the drugs and abusers. It consists of 22 items, answers are distributed in a Likert scale ranging from, I don't know, know to some extent, have fair knowledge and have strong background. Score ranged from 1, 2, 3, \& 4 respectivly. The lower score is 22 and the higher one is 88 .

\section{Scoring System}

Higher scores mean having good knowledge and lower score means knowledge deficit. Poor $\downarrow 44$ (> 50\%), Fair $(44-66)(50 \%-75 \%)$, Good ( $\uparrow 66)(<75 \%)$.

Part B: Consists of 9 statements, it measure attitude towards abusers, it consists of 2 reversed items which are 2 and 8.The higher the score, the greater positive attitude of the adolescents toward abuse and abusers. Scores ranged from 4, 3, 2, \& 1respectively.

\section{Scoring System}

Representing positive attitude, neutral attitude, negative attitude, and strongly negative attitude. Negative ( $\downarrow \mathbf{4 0 \%})$, Neutral (40-60\%), Positive ( $\uparrow 60 \%)$.

Part C: Consists of 6 items which measures adolescent's perceptions of seriousness of abuse and abusers. The higher score indicates adolescent's real perception of seriousness of the abuse and abusers. Statements 3, 4, 5 are reversed. Statements are recorded in Likert scale ranging from I did not agree, I don't know, agree, and strongly agree. Score ranged from 4, 3, 2, \& 1respectivly. Scoring System

Negative $(\downarrow 40 \%)$, Neutral (40-60\%), Positive ( $\uparrow 60 \%)$.

\subsection{Pilot Study}

A pilot study was carried out on $10 \%$ of the sample from different schools, to evaluate the clarity and applicability of the tool and necessary modifications were done based on their responses. The pilot study was also used to estimate the time needed to fill in the tool. Students who participated in the pilot study were later excluded from the main study sample.

\subsection{Validity:}

The study tools were tested for its content and face validity by a jury of five experts in the field of Psychiatry and Pediatric Nursing to evaluate items as well as the entire instrument as being relevant and appropriate in terms of the construct and if the items adequately measure all dimensions of the construct.

Reliability: chrompach alpha test $=0.8$

\subsection{Field Work}

An official letter issued from the Faculty of Nursing, Mansoura University was sent to the Ministry of Education and after that the executive of the schools, including the point and time table of the review to get consents to visit schools and direct the review. The health and psycho education intervention about addiction prevention was created in view of audit of related writing and apparatus appraisal (pre-test). Time plan was set up and the understudies were sorted out into 8 groups (20-30 students). The program was executed in school day beginning from 9.00 a.m. to 1.00 p.m., and instructive program built included 4 stages:

(1) Preparatory stage: The preliminary stage was done by utilizing the assessment tools after being revised and tested for general information about substance abuse prevention. Time expended for answering the study sheet ranged from 20-35 minutes. This phase lasted for 3 weeks.

(2) Planning stage: Based on the outcome acquired from the assessment phase, educational sessions were created after reviewing of related literature. Detected needs, requirements and deficiencies in knowledge and negative attitude and wrong perception regarding addiction and abusers. They were converted into aim and objectives of the health and psychoeducational sessions and an illustrated booklet was created by the researchers and offered to every member as reference.

(3) Implementation stage: The booklet was implemented in the form of sessions. The length of every session was distinctive according to students' response, time accessible, and the content of each session. Mostly every session took about 45-60 minutes. They included:

1. Health education about type of drugs, their actions, mode of use, side effects and complications [14,15].

2. Psychoeducation about correction of attitudes and perception of addiction and this through:

A. Consists of two techniques which are: 1 . Written emotional disclosure of students towards abusers as, fear, guilt, sadness etc.... 2. Brain storming about whether the abusers are victims (need help) or devils that need to be avoided [16,17].

B. Cognitive restructuring of the false perception and negative attitude towards addicts and addiction, including information about hazards of every substance, ways of addiction, difference between tolerance, addiction, habituation and dependence.

C. Examining inferences about if they are victims who need help or not, by explaining causes and theories of addiction and applying [18].

D. Examining cost benefits of supporting addict persons or avoiding them through examining community hazards ( through role play) [19].

(4) Evaluation stage: evaluation of the health and psycho educational sessions was done quickly after their implementation by contrasting the change in students' level of knowledge, and attitudes and perception through applying the similar apparatuses of pre-test as posttest [14].

Ethical considerations: Consent to participate in the study was obtained from the parents of school students of the study group. They were given an opportunity to refuse to participate and they were notified that they can withdraw at any stage of research without giving any 
reason. Also they were assured that, the information given will remain confidential and used for the research purpose only.

\subsection{Statistical Design}

The calculated data was analyzed and tabulated using "chi-square" for number and percentage distribution and correlation coefficient "r" was used; by using SPSS, version 16.0 to determine if there are statistically significance relations. A statistically significant difference was considered at $p$-value $p \leq 0.05$, and a highly statistically significant difference was considered at $\mathrm{p}$-value $\mathrm{p} \leq 0.001$.

\section{Results}

\section{Part I}

This Table 1 shows that, most of the sample size is from urban areas representing $60.8 \%$ of the population. Most of the study sample has from 1-3 brothers and sisters representing $71.7 \%$ and $64.1 \%$ respectively. Moreover, more than the third of the sample have a second birth order with a percentage of $42.5 \%$.
Table 1. Sociodemographic characterstics of technical school students

\begin{tabular}{|l|c|c|}
\hline Items & $\begin{array}{c}\text { Frequency } \\
\text { No= 240 }\end{array}$ & $\begin{array}{c}\text { Percentage } \\
\%\end{array}$ \\
\hline Residence & 146 & 60.8 \\
\hline Urban & 94 & 39.2 \\
\hline Rural & 240 & 100 \\
\hline Total & 172 & \\
\hline Brother number & 58 & 71.7 \\
\hline $1-3$ & 10 & 24.1 \\
\hline $4-6$ & 240 & 4.2 \\
\hline More than 6 & & 100 \\
\hline Total & 154 & \\
\hline Sister number & 59 & 64.1 \\
\hline $1-3$ & 27 & 24.6 \\
\hline $4-6$ & 240 & 11.3 \\
\hline more than 6 & & 100 \\
\hline Total & 48 & \\
\hline Birth orders & 104 & 20 \\
\hline First & 64 & 42,5 \\
\hline Second & 24 & 26.7 \\
\hline Third & 240 & 10.8 \\
\hline fourth and more & & 100 \\
\hline Total & & \\
\hline & & \\
\hline
\end{tabular}

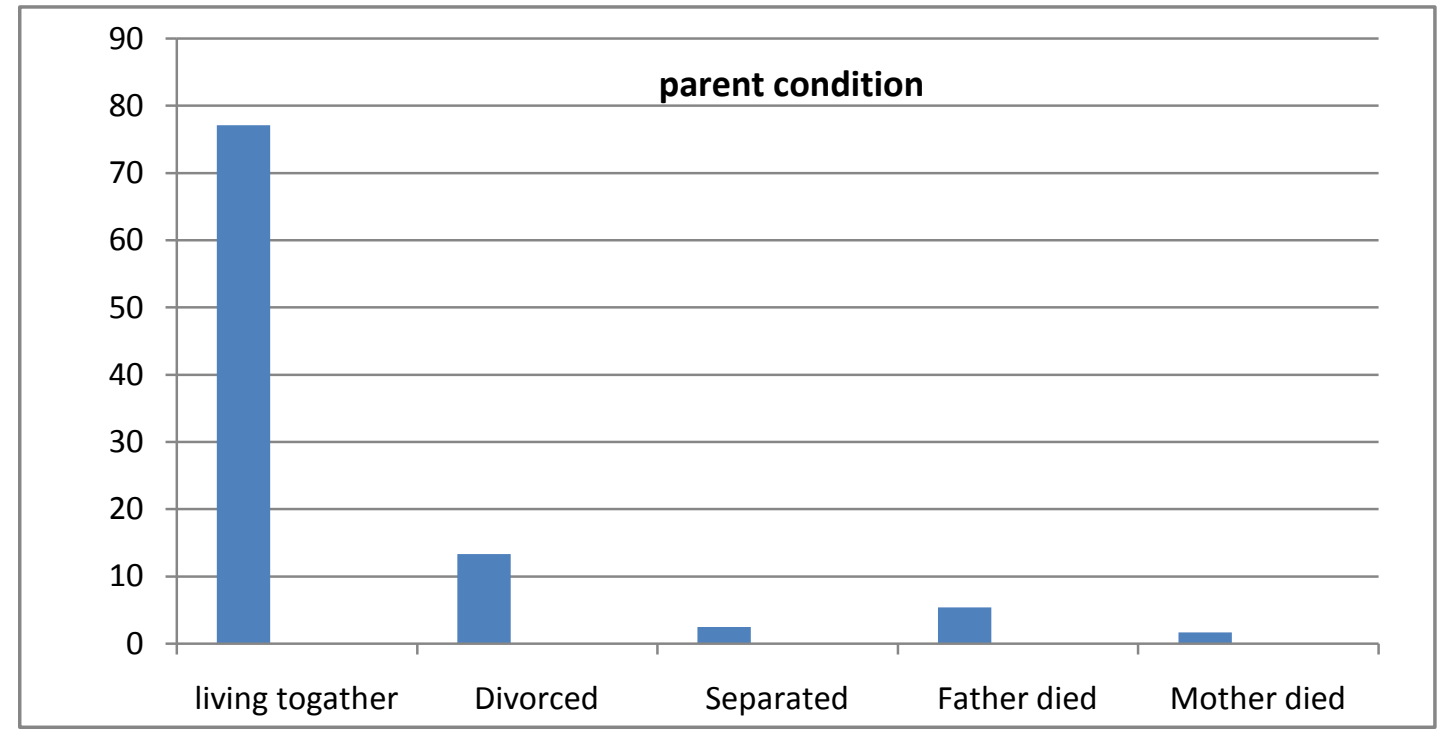

Figure 1. Sociodemographic characteristics of technical school adolescent students' parents

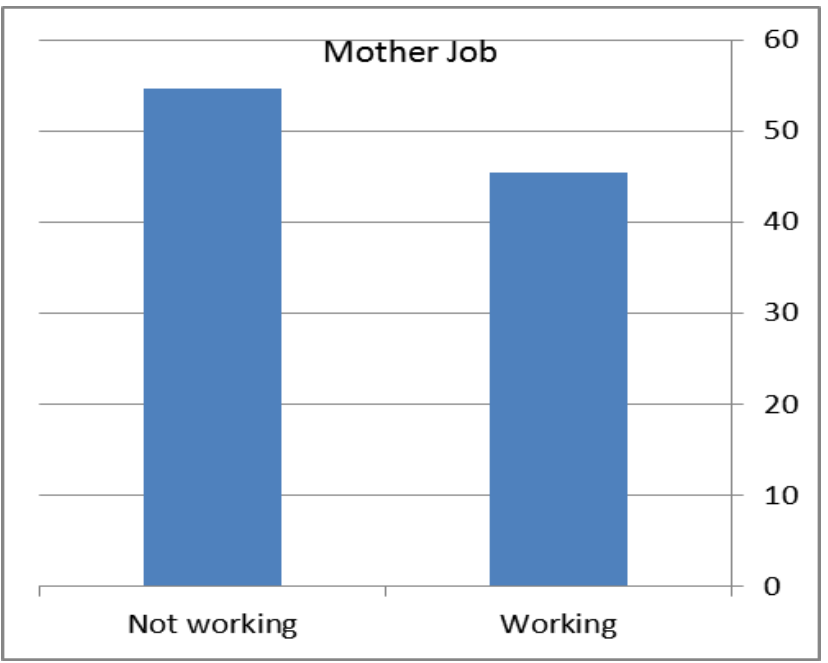

Figure 2.

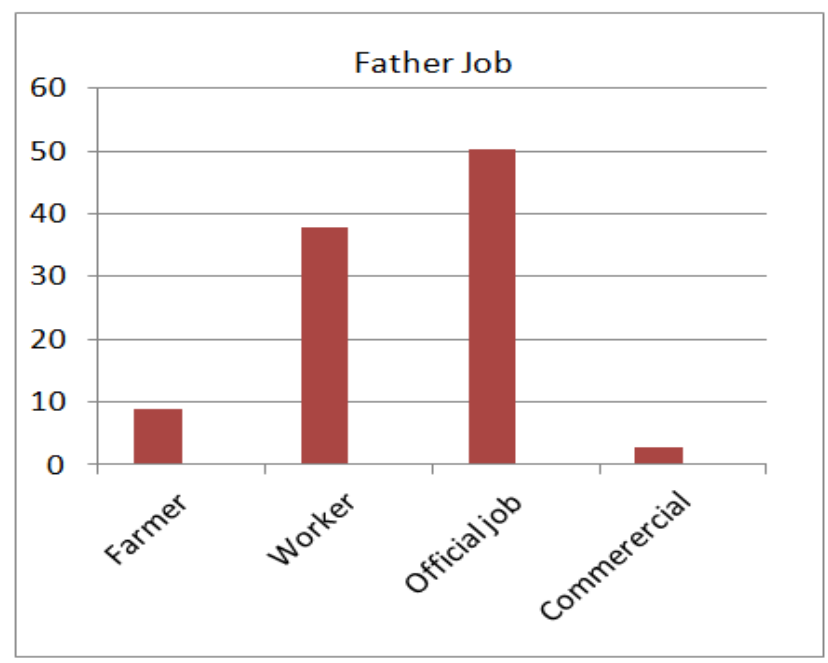

Figure 3. 


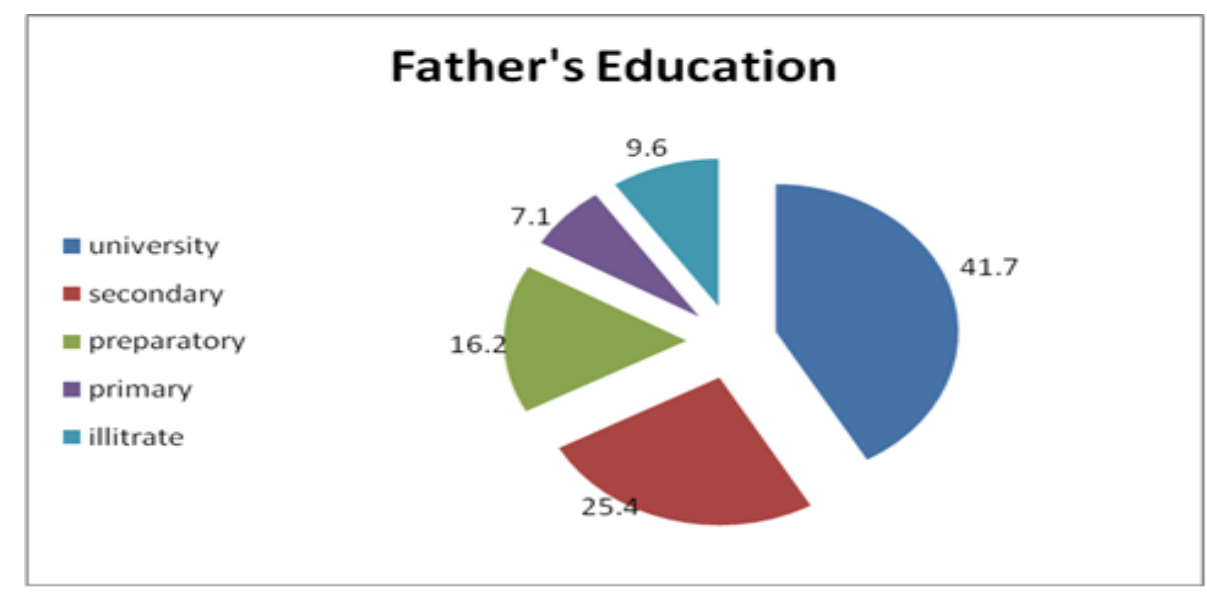

Figure 4.

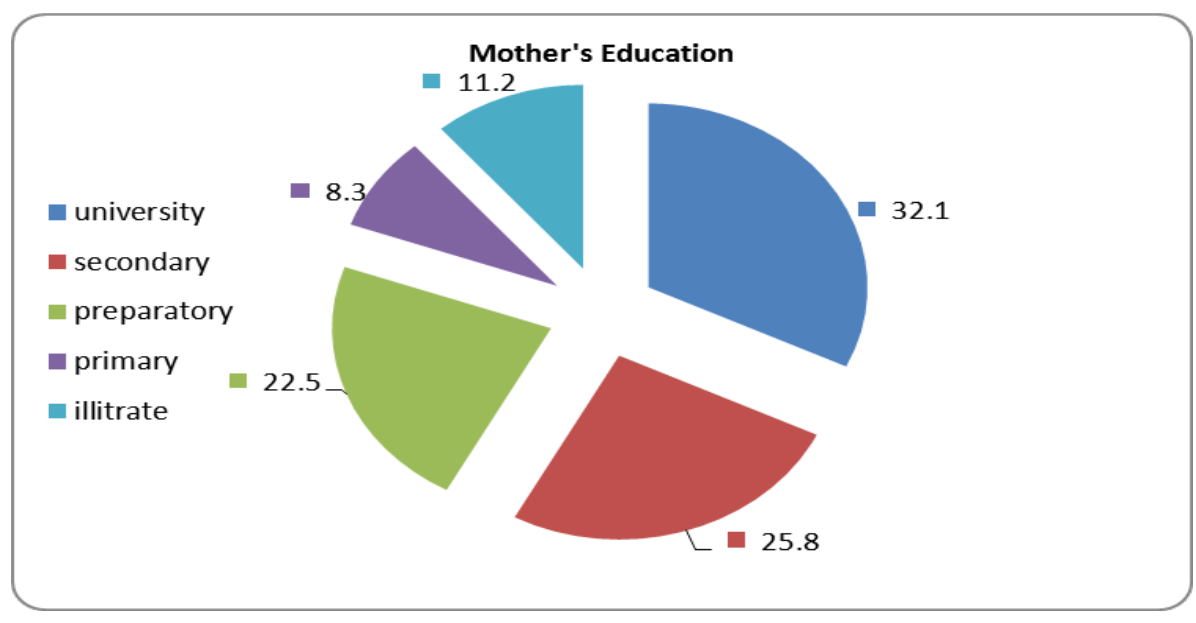

Figure 5.

Previous Figure 1, Figure 2, Figure 3 illustrate that more than half of the fathers of the studied adolescent students are working official job, representing $50.4 \%$ of the study sample. However, more than half of the studied adolescen students, their mothers are not working, representing $54.6 \%$ of the study sample. Moreover, more than three quadrant of the study sample parents are living together, representing $77.1 \%$ of the sample size.

This Figure 4 illustrates that majority of the fathers of the adolescents are secondary graduated representing $25.4 \%$ of the sample size.

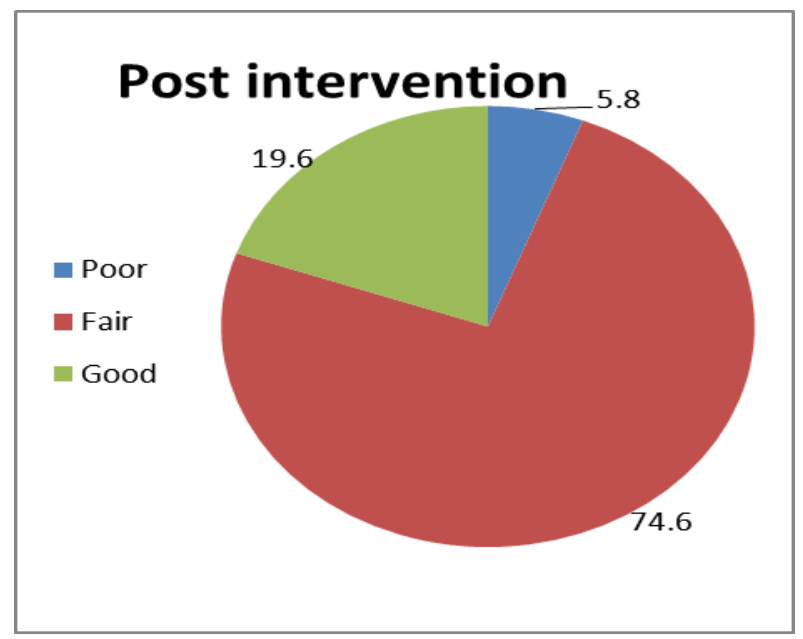

Figure 6 .
This Figure 5 illustrates that majority of the mothers of the study sample are university graduated representing $32.1 \%$ of the sample size.

\section{Part II}

Table 2: Ilustrates that there is statistically significant improvements in most of the adolescents' knowledge after implementation of the program.

Total knowledge scores of technical school adolescent students related to substance abuse pre and postintervention

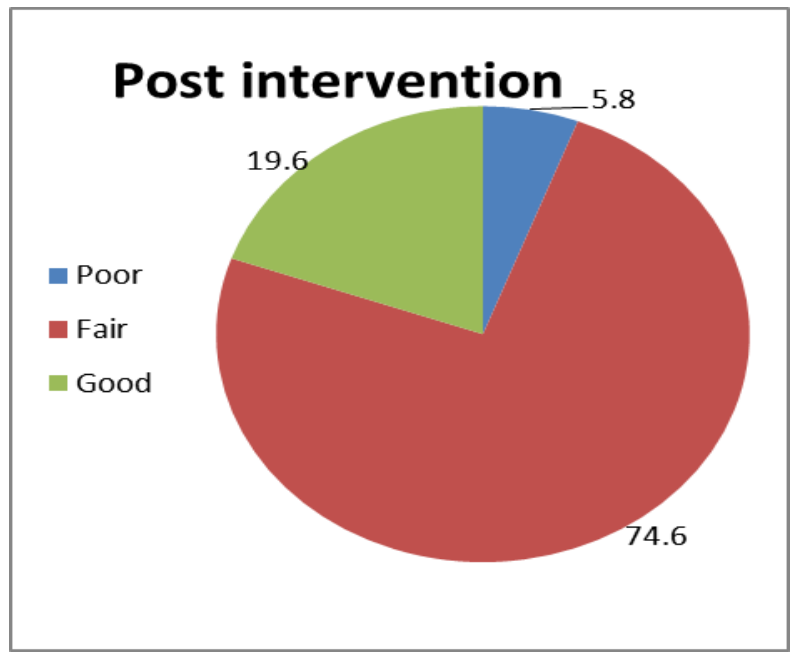

Figure 7. 
These Figure 6, Figure 7 illustrate that, there is statistically significant improvement in the level of knowledge after intervention, with $\mathrm{p}=0.000$.

Table 3 shows that many of adolescents negative attitudes have improved after education, regarding over valuing their problems to get sympathy, seeing addicts as dangerous person, with $\mathrm{p}=0.004,0.006$. Regarding living near an addict, and viewing the society as tolerable for addicts, there were highly statistically improvement with $\mathrm{p}=0.000$.

Table 4 illustrated that; There is statistically significant improvement in adolescents' perception towards abuse and abusers. Improvement included perception of using hallucinogens from time to time is not dangerous, using heroin from time to time is not really dangerous and regular use of cannabis is not as dangerous as heroin, with $\mathrm{p}=0.000$.

Table 2. Mean scores of technical school adolescent students' knowledge about substance abuse pre and post intervention

\begin{tabular}{|c|c|c|c|c|c|}
\hline \multicolumn{2}{|c|}{ Domain } & \multirow{2}{*}{$\begin{array}{c}\begin{array}{c}\text { Pre intervention } \\
(\mathbf{N o}=\mathbf{2 4 0}) \\
(\text { Mean } \pm \text { SD) }\end{array} \\
2.8208 \pm .98375\end{array}$} & \multirow{2}{*}{$\begin{array}{c}\begin{array}{c}\text { Post intervention } \\
(\mathbf{N o}=\mathbf{2 4 0}) \\
(\text { Mean } \pm \text { SD })\end{array} \\
2.9583 \pm .95414\end{array}$} & \multirow{2}{*}{\begin{tabular}{|c|}
$\begin{array}{c}\text { Paired } \\
\text { t- test }\end{array}$ \\
-1.614 \\
\end{tabular}} & \multirow{2}{*}{$\begin{array}{c}\text { P-value } \\
.108\end{array}$} \\
\hline 1 & Tea, coffee, and smoking are dangerous as other types of substance abuse & & & & \\
\hline 2 & All illegal drugs are harmful to your health & $2.7750 \pm 1.07822$ & $2.8500 \pm 1.09124$ & -.733 & .464 \\
\hline 3 & Our society is very tolerant towards drug abusers & $2.1292 \pm 1.01247$ & $2.0542 \pm 1.04360$ & .795 & .427 \\
\hline 4 & If you tried drugs until once, you became addicted & $2.2708 \pm .94492$ & $2.3750 \pm 1.11335$ & -1.181 & .239 \\
\hline 5 & Most young people today use cannabis & $2.6417 \pm .91748$ & $2.5857 \pm 1.11318$ & .528 & .561 \\
\hline 6 & Alcohol abuse causes more problems in society than drug abuse. & $2.6583 \pm .99367$ & $2.7167 \pm 1.13656$ & -.634 & .527 \\
\hline 7 & $\begin{array}{l}\text { Treatment should be given only to drug addicts who intend to abandon } \\
\text { addiction }\end{array}$ & $2.6417 \pm 1.02108$ & $2.5458 \pm 1.08141$ & .966 & .335 \\
\hline 8 & Treatment should be available to all drug addicts, according to their need & $2.6917 \pm .93554$ & $2.9333 \pm 1.11087$ & -2.791 & .006 \\
\hline 9 & The reason for the drug problem is violent methods with addicts & $2.2083 \pm .75319$ & $2.5083 \pm .972319$ & -4.027 & .000 \\
\hline 10 & Most people are concerned about the drug problem in Egypt & $2.0625 \pm .77098$ & $2.2833 \pm 1.11049$ & -2.501 & .013 \\
\hline 11 & Using hallucinogens from time to time is not really dangerous & $1.8851 \pm .86701$ & $1.9489 \pm 1.01986$ & -.730 & .466 \\
\hline 12 & Many drug addicts exaggerate their problems to get sympathy & $2.1875 \pm .92967$ & $2.7833 \pm 1.07605$ & -7.284 & .000 \\
\hline 13 & It is normal for young people to try drugs at least once & $2.3708 \pm 1.95984$ & $2.6917 \pm 1.078303$ & -2.052 & .041 \\
\hline 14 & Drug awareness should begin in primary school & $2.8373 \pm 2.30396$ & $3.1000 \pm .95418$ & -1.638 & .103 \\
\hline 15 & Drug-related crime is a major problem in Egypt today & $2.4208 \pm .91591$ & $2.8083 \pm 1.10757$ & -4.556 & .000 \\
\hline 16 & Reports of drug abuse among young people are exaggerated by media & $2.2125 \pm .99825$ & $2.5083 \pm 1.07096$ & -3.508 & .001 \\
\hline 17 & $\begin{array}{l}\text { Regular use of cannabis is a risk to your health, such as regular use for } \\
\text { heroin }\end{array}$ & $2.4208 \pm 1 . .05991$ & $2.7875 \pm 1.05132$ & -3.944 & .000 \\
\hline 18 & Personally I know some who take cannabis. & $2.1417 \pm .99198$ & $2.8583 \pm .93106$ & -8.085 & .000 \\
\hline 19 & I have used one kind of drugs & $1.9042 \pm 1.02029$ & $2.7250 \pm 1.01835$ & -9.765 & .000 \\
\hline 20 & Personally I know someone who has a / problem with drugs. & $2.0250 \pm 1.06258$ & $2.8375 \pm 1.08751$ & -8.104 & .000 \\
\hline 21 & Most young people today are taking cannabis. & $2.2833 \pm 1.02833$ & $2.8500 \pm 1.00334$ & -5.981 & .000 \\
\hline 22 & Alcohol abuse causes more problems in society than drug abuse & $2.3417 \pm 1.03896$ & $2.6458 \pm 1.12204$ & -3.282 & .001 \\
\hline
\end{tabular}

Table 3. Mean scores of technical schools adolescent students' attitude towards substance abuse pre and post intervention

\begin{tabular}{|c|c|c|c|c|c|}
\hline \multicolumn{2}{|c|}{ Domains } & \multirow{2}{*}{$\begin{array}{c}\text { Pre intervention } \\
(\mathbf{N o =} \mathbf{2 4 0}) \\
(\text { Mean } \pm \text { SD) } \\
2.7583 \pm 0.91474\end{array}$} & \multirow{2}{*}{$\begin{array}{c}\text { Post intervention } \\
(\mathbf{N o = 2 4 0 )} \\
(\text { Mean } \pm \text { SD) } \\
2.7708 \pm 1.21082\end{array}$} & \multirow{2}{*}{$\begin{array}{c}\begin{array}{c}\text { Paired } \\
\text { t- test }\end{array} \\
-.124\end{array}$} & \multirow{2}{*}{$\begin{array}{c}\text { P-value } \\
.901\end{array}$} \\
\hline 1 & It is necessary to be addicted to addict. & & & & \\
\hline 2 & Drug addicts do not have a fair chance of progress in society. & $2.2667 \pm .93050$ & $.3750 \pm 1.1575$ & -1.143 & .254 \\
\hline 3 & People who end up with the drug problem blame only themselves. & $2.3792 \pm .8972$ & $2.2083 \pm 1.16357$ & 1.830 & .069 \\
\hline 4 & Drug addicts really scare me. & $2.7292 \pm 1.02152$ & $2.5750 \pm 1.10989$ & 1.964 & .092 \\
\hline 6 & Almost all drug addicts are dangerous. & $2.5667 \pm .95272$ & $2.8083 \pm 1.10387$ & 2.798 & .006 \\
\hline 7 & It bothers me to live near someone addicted & $2.5083 \pm 1.09005$ & $2.9917 \pm 1.13886$ & 4.369 & .000 \\
\hline 8 & Our society is very tolerant towards drug abusers. & $2.1985 \pm .98481$ & $2.7958 \pm .99580$ & 6.481 & .000 \\
\hline 9 & The man who is abusing me makes me nervous. & 2. $4917 \pm 1.10151$ & $2.5042 \pm 1.17860$ & .120 & .904 \\
\hline
\end{tabular}

Table 4. Mean scores of technical schools students'perception towards substance abuse pre and post intervention

\begin{tabular}{|c|c|c|c|c|c|}
\hline \multicolumn{2}{|c|}{ Domain } & \multirow{2}{*}{$\begin{array}{c}\begin{array}{c}\text { Pre intervention } \\
(\mathbf{N o}=\mathbf{2 4 0}) \\
(\text { Mean } \pm \text { SD })\end{array} \\
2.3833 \pm 1.03644\end{array}$} & \multirow{2}{*}{$\begin{array}{c}\begin{array}{c}\text { Post intervention } \\
\text { (No=240) } \\
(\text { Mean } \pm \text { SD) }\end{array} \\
2.4167 \pm 1.26810\end{array}$} & \multirow{2}{*}{$\begin{array}{c}\begin{array}{c}\text { Paired } \\
\text { t- test }\end{array} \\
-.320\end{array}$} & \multirow{2}{*}{$\begin{array}{r}\text { P-value } \\
.749 \\
\end{array}$} \\
\hline 1 & All drugs are equally dangerous & & & & \\
\hline 2 & If i tried drugs even once, I was hooked & $2.0333 \pm .87679$ & $1.9417 \pm 1.17716$ & .965 & .336 \\
\hline 3 & Incidental use of cannabis is not really dangerous. & $1.7833 \pm .86498$ & $1.8000 \pm 1.13962$ & -.170 & .865 \\
\hline 4 & Using hallucinogens from time to time is not really dangerous & $1.7667 \pm .84073$ & $2.4167 \pm 1.09837$ & -7.627 & .000 \\
\hline 5 & Use heroin sometimes is not really dangerous. & $1.6500 \pm .87408$ & $2.6708 \pm 1.19797$ & -10.754 & .000 \\
\hline 6 & Regular use of cannabis is not as dangerous to health as heroin. & $2.2958 \pm .98524$ & $2.9292 \pm 1.12372$ & -6.493 & .000 \\
\hline
\end{tabular}


This Table 5 illustrates that fathers' education is strongly correlated positively with adolescents poor knowledge with $p=0.000$. Also, positively correlated with their neutral perception for addiction.

This Table 6, reveals to the adolescents fair knowledge, neutral attitude and neutral perception are strongly positively correlated with their mothers' education.
This Table 7 illustrates that adolescents' fair knowledge and neutral perceptions are strongly positively correlated with fathers' job, representing $\mathrm{p}=0.000$. However, adolescents neutral attitude are correlated with their father's education with $\mathrm{p}=0.05$.

Table 8 shows that, adolescents fair knowledge, neutral perceptions are strongly positively correlated with mothers' occupation, $p=0.000$, and 0.003 respectively.

Table 5. Relationship between father's education, Total knowledge scores, attitude and perception of technical schools adolescent students postintervention

\begin{tabular}{|c|c|c|c|c|c|c|c|c|c|c|c|c|}
\hline & \multicolumn{10}{|c|}{ Father's Education } & \multirow[b]{3}{*}{$\mathbf{X}^{2}$} & \multirow[b]{3}{*}{$\mathbf{P}$} \\
\hline & \multicolumn{2}{|c|}{ University } & \multicolumn{2}{|c|}{ Secondary } & \multicolumn{2}{|c|}{ Preparatory } & \multicolumn{2}{|c|}{ Primary } & \multicolumn{2}{|c|}{ Illiterate } & & \\
\hline & $\begin{array}{c}\text { No. } \\
(100)\end{array}$ & $\%$ & $\begin{array}{l}\text { No. } \\
(61)\end{array}$ & $\%$ & $\begin{array}{l}\text { No. } \\
\text { (39) }\end{array}$ & $\%$ & $\begin{array}{l}\text { No. } \\
(17)\end{array}$ & $\%$ & $\begin{array}{l}\text { No. } \\
\text { (23) }\end{array}$ & $\%$ & & \\
\hline TKS post: & \multirow{2}{*}{0} & \multirow{2}{*}{0} & \multirow{2}{*}{5} & \multirow{2}{*}{8.2} & \multirow{2}{*}{5} & \multirow{2}{*}{12.8} & \multirow{2}{*}{2} & \multirow{2}{*}{11.8} & \multirow{2}{*}{2} & \multirow{2}{*}{8.7} & \multirow{2}{*}{2.347} & \multirow{2}{*}{.000} \\
\hline Poor & & & & & & & & & & & & \\
\hline Fair & 77 & 77 & 43 & 70.5 & 30 & 76.9 & 13 & 76.4 & 17 & 73.9 & & \\
\hline Good & 23 & 23 & 13 & 21.3 & 4 & 10.3 & 2 & 11.8 & 4 & 17.4 & & \\
\hline $\begin{array}{l}\text { Attitude post } \\
\text { Negative }(\downarrow \mathbf{4 0} \%)\end{array}$ & 2 & 2 & 4 & 6.6 & 3 & 7.7 & 2 & 11.8 & 2 & 8.7 & 1.061 & .09 \\
\hline Neutral (40-60\%) & 36 & 36 & 27 & 44.3 & 22 & 56.4 & 7 & 41.2 & 7 & 30.4 & & \\
\hline Positive $(\uparrow 60 \%)$ & 62 & 62 & 30 & 49.1 & 14 & 35.9 & 8 & 47 & 14 & 60.9 & & \\
\hline $\begin{array}{l}\text { Perception post } \\
\text { Negative }(\downarrow 40 \%)\end{array}$ & 13 & 13 & 5 & 8,2 & 10 & 25.6 & 0 & 0 & 2 & 8.7 & & \\
\hline Neutral (40-60\%) & 59 & 59 & 36 & 59 & 14 & 35.9 & 12 & 70.6 & 8 & 34.8 & 90.116 & .000 \\
\hline Positive $(\uparrow 60 \%)$ & 28 & 28 & 20 & 32.8 & 15 & 38.5 & 5 & 29.4 & 13 & 56.5 & & \\
\hline
\end{tabular}

Table 6. Relationship between mother's education, total knowledge score, attitude and perception of technical schools students post intervention

\begin{tabular}{|c|c|c|c|c|c|c|c|c|c|c|c|c|}
\hline & \multicolumn{10}{|c|}{ Mother's Education } & \multirow[b]{3}{*}{$\mathbf{X}^{2}$} & \multirow[b]{3}{*}{$\mathbf{P}$} \\
\hline & \multicolumn{2}{|c|}{ University } & \multicolumn{2}{|c|}{ Secondary } & \multicolumn{2}{|c|}{ Preparatory } & \multicolumn{2}{|c|}{ Primary } & \multicolumn{2}{|c|}{ Illiterate } & & \\
\hline & $\begin{array}{l}\text { No. } \\
\text { (77) }\end{array}$ & $\%$ & $\begin{array}{l}\text { No. } \\
\text { (62) }\end{array}$ & $\%$ & $\begin{array}{l}\text { No. } \\
\text { (54) }\end{array}$ & $\%$ & $\begin{array}{l}\text { No. } \\
\text { (20) }\end{array}$ & $\%$ & $\begin{array}{l}\text { No. } \\
\text { (27) }\end{array}$ & $\%$ & & \\
\hline TKS post: & & & & & & & & & & & & \\
\hline Poor & 4 & 5.2 & 5 & 8 & 2 & 3.7 & 3 & 15 & 0 & 0 & & \\
\hline Fair & 54 & 70.1 & 48 & 77.4 & 42 & 77.8 & 15 & 75 & 21 & 77.8 & 2.702 & .000 \\
\hline Good & 19 & 24.7 & 9 & 14.5 & 10 & 18.5 & 2 & 10 & 6 & 22.2 & & \\
\hline $\begin{array}{l}\text { Attitude post } \\
\text { Negative }(\downarrow \mathbf{4 0 \%})\end{array}$ & 3 & 3.9 & 3 & 4.8 & 4 & 7.4 & 0 & 0 & 1 & 3.7 & & \\
\hline Neutral (40-60\%) & 22 & 28.6 & 22 & 35.5 & 30 & 55.6 & 13 & 65 & 12 & 44.4 & 1.290 & .003 \\
\hline Positive $(\uparrow 60 \%)$ & 52 & 67.5 & 37 & 59.7 & 20 & 37 & 7 & 35 & 14 & 51.9 & & \\
\hline $\begin{array}{l}\text { Perception post } \\
\text { Negative }(\downarrow 40 \%)\end{array}$ & 4 & 5.2 & 7 & 11.3 & 14 & 25.9 & 3 & 15 & 2 & 7.4 & & \\
\hline Neutral (40-60\%) & 56 & 72.7 & 25 & 40.3 & 31 & 57.4 & 7 & 35 & 14 & 51.9 & 1.355 & 0.00 \\
\hline Positive $(\uparrow 60 \%)$ & 17 & 22.1 & 30 & 48.4 & 9 & 16.7 & 10 & 50 & 11 & 40.7 & & \\
\hline
\end{tabular}

Table 7. Relationship between father's occupation, total knowledge score, attitude and perception of technical schools adolescent students post intervention

\begin{tabular}{|c|c|c|c|c|c|c|c|c|c|c|}
\hline & \multicolumn{10}{|c|}{ Father's Occupation } \\
\hline & \multicolumn{2}{|c|}{ Farmer } & \multicolumn{2}{|c|}{ Worker } & \multicolumn{2}{|c|}{ Professional } & \multicolumn{2}{|c|}{ Commercial } & \multirow[b]{2}{*}{$\mathbf{X}^{2}$} & \multirow[b]{2}{*}{$\mathbf{P}$} \\
\hline & $\begin{array}{l}\text { No. } \\
(21)\end{array}$ & $\%$ & $\begin{array}{l}\text { No. } \\
(91)\end{array}$ & $\%$ & $\begin{array}{l}\text { No. } \\
\text { (121) }\end{array}$ & $\%$ & $\begin{array}{l}\text { No. } \\
\text { (7) }\end{array}$ & $\%$ & & \\
\hline TKS post: & & & & & & & & & & \\
\hline Poor & 3 & 14.3 & 5 & 5.5 & 4 & 3.3 & 2 & 28.6 & & \\
\hline Fair & 18 & 85.7 & 67 & 73.6 & 88 & 72.7 & 5 & 71.4 & 2.244 & .000 \\
\hline Good & 0 & 0 & 19 & 20.9 & 29 & 24 & 0 & & & \\
\hline $\begin{array}{l}\text { Attitude post } \\
\text { Negative }(\downarrow 40 \%)\end{array}$ & 1 & 4.8 & 3 & 3.3 & 8 & 6.6 & 1 & 14.2 & & \\
\hline Neutral (40-60\%) & 14 & 66.6 & 4 & 4.4 & 37 & 30.6 & 4 & 57.1 & 86.213 & .04 \\
\hline Positive $(\uparrow 60 \%)$ & 6 & 28,6 & 84 & 92.3 & 76 & 62.8 & 2 & 28.7 & & \\
\hline $\begin{array}{l}\text { Perception post } \\
\text { Negative }(\downarrow 40 \%) \\
\end{array}$ & 3 & 14.3 & 16 & 17.6 & 11 & 9.1 & 0 & 0 & & \\
\hline Neutral (40-60\%) & 12 & 57.1 & 47 & 51.6 & 79 & 65.3 & 4 & 57.1 & 90.622 & 0.00 \\
\hline Positive $(\uparrow 60 \%)$ & 6 & 28.6 & 28 & 30.8 & 31 & 25.6 & 3 & 42.9 & & \\
\hline
\end{tabular}


Table 8. Relationship between mother's occupation, total knowledge score, attitude and perception of technical schools adolescent students post intervention

\begin{tabular}{|c|c|c|c|c|c|c|}
\hline & \multicolumn{2}{|c|}{ Working } & \multicolumn{2}{|c|}{ Not Working } & \multirow[b]{2}{*}{$X^{2}$} & \multirow[b]{2}{*}{$\mathbf{P}$} \\
\hline & $\begin{array}{l}\text { No. } \\
\text { (109) }\end{array}$ & $\%$ & $\begin{array}{l}\text { No. } \\
\text { (131) }\end{array}$ & $\%$ & & \\
\hline TKS post: & & & & & & \\
\hline Poor & 7 & 6.4 & 7 & 5.3 & & \\
\hline Fair & 82 & 75.2 & 98 & 74.8 & 71.113 & .000 \\
\hline Good & 20 & 18.4 & 26 & 19.9 & & \\
\hline $\begin{array}{l}\text { Attitude post } \\
\text { Negative ( } \downarrow \mathbf{4 0 \%})\end{array}$ & 3 & 2.8 & 10 & 7.6 & & \\
\hline Neutral (40-60\%) & 51 & 46.8 & 43 & 32.8 & 26.933 & .2 \\
\hline Positive $(\uparrow 60 \%)$ & 55 & 50.4 & 78 & 59.6 & & \\
\hline $\begin{array}{l}\text { Perception post } \\
\text { Negative }(\downarrow 40 \%)\end{array}$ & 19 & 17.43 & 11 & 8.4 & & \\
\hline Neutral (40-60\%) & 65 & 59.63 & 77 & 58.8 & 29.751 & .003 \\
\hline Positive $(\uparrow 60 \%)$ & 25 & 22.94 & 43 & 32.8 & & \\
\hline
\end{tabular}

\section{Discussion}

Substance abuse is a major problem in Egypt, due to rapidly growing and changing patterns of substance use. This approached as a method of preventing abuse.

Part I: Regarding socio demographic data, most of the study samples are from urban areas representing about two thirds of the sample. This influenced the knowledge of adolescents about abuse and their attitude towards abusers. As most of them have a relative, neighbor or even know someone who abuse, in contrast to adolescents who live in rural areas. This agrees with what Hamdi E stated that People of rural origins (29.3\%) are the least at using substance [20].

Part II: Regarding adolescents' knowledge, attitude, and perception pre and post intervention. Regarding adolescents knowledge, there were statistically significant improvements in the level of knowledge after implementation of the program in many forms. After implementation of the program adolescents level of poor knowledge have decreased about the tenth of their number. Moreover, adolescents with good knowledge have increased about sixth of their number after implementation of the program. This result could be related to effect of comprehensive counseling which included changing concepts related to abuse. The sessions included definition of the abuse, tolerance, habituation, and addiction and difference between them. Description of symptoms, side effects and complication of each type o substance abuse. Hence, adolescents' knowledge changed about the idea of "use of analgesics as most of the adolescents don't consider them abuse". This agrees with Haddad et al., who found that there is a deficiency in the students' knowledge and believes regarding addiction. Moreover describing symptoms of addiction has changed their view of people as they could see before. Describing causes of addiction increased their knowledge with addictive behavior. Also, Hadad et al., stated that nursing intervention helped in improving students' knowledge, awareness, and their attitude toward substance abuse, and abuser [2]. Congruent with what researches said, west encourages us to think differently about people and populations with substance use problems [22].

Considering drinking of tea, coffee, and smoking are dangerous, there was no change in the knowledge of the adolescents after intervention than pre. This could be rationalized as most of our cultures consider coffee, tea and even smoking not a form of addiction as their side effects appears on long run. Moreover they consider stopping them is not making withdrawal symptoms as other drugs [20].

There were statistically significant improvement in adolescent knowledge regarding (Alcohol abuse causes more problems in society than drug abuse) with $\mathrm{p}=0.000$. This agrees with Kerry et al. (2013) who reported substantial evidence relating to the positive effects of school-based alcohol education and life-skills programs on school children's alcohol related-knowledge and attitude [23]. Adolescents knowledge after intervention has improved than pre intervention regarding cannabies (regular use of cannabies is as risk to your health as heroin) (Table 3) with $p=0.000$. This rationalzed as Cannabis in Egypt is illegal, but its use is a part of the common culture in the country for many people [24].

Also fair knowledge of the adolescents after counseling could be regarded to strong correlation between mothers' level of education (university and secondary educated) and adolescents' knowledge regarding addiction with $p=0.00$. As educated mothers could have more knowledge than non educated or moderately educated mothers.

Regarding adolescents' attitude towards addicts and addiction, there is statistically significant improvement in the adolescents' attitude regarding believes such as (Almost all drug addicts are dangerous), (It bothers me to live near someone addicted), (Our society is very tolerant towards drug abusers), with $\mathrm{p}=0.000$. Using cognitive restructuring and examining inferences about if addicts are victims who need help or not was a helpful method to change the attitude of adolescents towards addicts. As most of adolescents use selective abstraction about any situation they expose to and make a generalization and forming an attitude towards the situation or objects they exposed to [19]. This result agrees with Pooley etal., who said that environmental educators interested in changing environmental attitudes, emotions and beliefs, rather than knowledge, need to be targeted as sources of information on which to base their environmental programs [25].

Regarding perception of the adolescents on the severity of addiction and abusers, it was found that, there is statistically significant improvement in adolescents' perception 
towards abuse and abusers. Improvement included perception of using hallucinogens from time to time is not dangerous, using heroin from time to time is not really dangerous and regular use of cannabis is not as dangerous as heroin, with $\mathrm{p}=0.000$. This explained as an effect to cognitive restructuring and role play techniques. This agrees with Beck, who said that memory restructuring and role-playing techniques are helpful to elicit effects associated with and restructure painful memories of events that shaped unhelpful core beliefs [26].

Also the results stated that adolescents' neutral attitudes for danger of abuse and abusers are strongly correlated with mothers' education with $\mathrm{p}=0.003$. This result explains some negative adolescents' attitude toward addicts after counseling. These attitudes are, it is necessary to be addicted to addict. Drug addicts do not have a fair chance of progress in society. People who end up with the drug problem blame only themselves. This could be explained as parents' negative attitude toward addicts had a significant effect on their adolescents' attitude toward addicts. This agrees with what Erabs et al., said that authoritative mothers adopt positive attitude toward education course positively influencing the education course attitude of the adolescents [27,28]. Moreover, most participants acquired their information from multiple sources but rarely referred to schools as a source of structured information on drugs or the harms of using them which could explain why most participants called for carrying out school-led awareness programmers and specialized education classes. This finding confirms the importance of incorporating drug education into schools' curricula [29].

Part III: Regarding correlation between adolescents' knowledge, perception, attitude, and their fathers' and mothers' education and occupation. Regarding correlation between father, mother education and level of knowledge, attitude and perception for addiction, the poor knowledge and neutral perception of the adolescent strongly correlated with their father education $p=0.000$. This could be regarded to the period of adolescents and formation of autonomy and deciding their way of thinking which affected by many factors from which is parents' education [27]. Lastly fair knowledge and neutral perception of the students were strongly correlated with parents (mother and father) occupation. This could be rationalized as parents work affecting on their knowledge, perception of addiction and addicts and hence, their adolescents acquire the same perception and knowledge from them [30,31].

\section{Conclusion}

Most of sample size are from urban areas, and living with their parents.

Adolescents have poor knowledge, attitude and perception regarding substance abuse pre intervention. Interventions including health and psycho-education have effective results on students' knowledge, attitude, and perceptrion of substance abuse. Poor knowledge of adolescents regarding substance abuse is strongly correlated with fatherS' education. Fair knowledge and neutral perception of the students toward addiction were strongly correlated with parents (mother and father) occupation.

\section{Recommendations}

1. Frequent assessments of adolescents' knowledge, attitude and perception regarding substance abuse.

2. Assessing sources of students information and providing frequent educational program for adolecents regarding substance abuse among Egyptian schools.

3. Collaboration of ministry of health with ministry of information in providing intervention program targeting adolescents and school students for prevention of abuse.

\section{References}

[1] Howard A. Liddle, Cynthia L. Rowe, Alina Gonzalez BA et al Changing Provider Practices, Program Environment, and Improving Outcomes by Transporting Multidimensional Family Therapy to an Adolescent Drug Treatment Setting. American journal of addiction; 2006, Volume 15, Issue s1Pages: s1-s143.

[2] Layla Alhyas, Naseeba Al Ozaibi,Amna Almarzouqi, Ayesha Alhosani and Hamad Al Ghaferi. Adolescents' perception of substance use and factors influencing its use: a qualitative study in Abu Dhabi .Journal of the Royal Society of Medicine Open; 2015, Vol. 6(2) 1-12.

[3] Abdel Salous University of Kentucky, abdel.salous@uky.edu Hatim A. Omar University of Kentucky, hatim.omar@uky.edu. Substance Abuse among Adolescents. 2010. Future Of Palm Beach (2014): Contributing factors of drug abuse, Retrieved from: http://www.Futuers of palms beach .com/drug-abuse/contributing factors.

[4] Leitner, M., Shapland, J., \& Wiles, P. Drug usage and drugs prevention: the views and habits of the general public. (1993). London: HMSO.

[5] HARRIS CHAIKLIN. Attitudes, Behavior, and Social Practice. Journal of Sociology \& Social Welfare, March 2011, Volume XXXVIII, Number 1 .

[6] Coggans, N., Shewan, D., Henderson, M., \& Davies, J.. National evaluation of drug education in Scotland. London: Institute for the Study of Drug Dependence. (1991).

[7] Hernandez, Alma Elizabeth and Araiza, Stephanie Michelle, "Beliefs About Substance Abuse Among Adolescents: What Works?” Electronic Teses, Projects, and Dissertations. (2014), Paper 61. 6. Esc. Anna Nery vol.18 no.2 Rio de Janeiro Apr./June 2014.

[8] Patestos C, Patterson K. Substance abuse prevention: the role of the school nurse across the continuum of care. NASN Sch Nurse. 2014 Nov; 29(6): 310-4.

[9] Bryan, A., Moran, R., Farrell, E., \& O'Brien, M. Drug-Related Knowledge, Attitudes and Beliefs in Ireland: Report of a Nation-Wide Survey. Dublin: The Health Research Board. Contact Detail. 2000.

[10] Rabie, et al., Addiction Prevention: Socio demographic Indicators for Substance Use and Abuse in Egypt. April 2016, Vol.:4, Issue: 1.

[11] Dawson,B.D., \& Trapp,R.G. (2001): Reading the medical literature: Basic \& Clinical Biostatistics. Lange Medical Book/ McGraw-Hill. Medical Publication Division, New York. (3rd ed) Ch. 7-9, Pp. 161-218 and Ch. 13, 305-314.

[12] Drug Trade in Egypt Amounts to Half of State Budget: Baseera Research. EGYPTIAN STREETS. SEPTEMBER 5, 2016.

[13] Susan T, Christopher L, Judy T, Louise R, Vincus A,et al. A comparison of current practice in school-based substance use prevention programs with meta-analysis finding. Prev Sci 2003; 4(1): 1-14.

[14] Case S and Haines K. Promoting prevention: preventing youth drug use in Swansea, UK by targeting risk and protective factors. J Subs Use 2003; 8: 8243-8251.

[15] White, A. M. (2005). The changing adolescent brain. Education Canada. Downloaded from www.cea-ace.ca/media

[16] Johnston, L. D., O’Malley, P. M., Bachman, J. G., \& Schulenberg, J. E. (2008). Monitoring the future national survey results on drug use, 1975-2007: Volume I, secondary school students (NIH Publication No. 08-6418A). Bethesda, MD: National Institute on Drug Abuse. 
[17] Beck, J. S. (2011). Cognitive behavior therapy: Basics and beyond (2nd ed.). New York, NY: Guilford Press.

[18] Effective strategies and interventions for adolescents in a child protection context Authors Dr Virginia Schmied (Centre for Parenting and Research) Lucy Tully (Centre for Parenting and Research) Centre for Parenting \& Research Service System Development Division. NSW Department of Community Services. 2009.

[19] Source: Beck, J. (1995). Cognitive therapy: Basics and beyond New York: Guilford press.

[20] Hamdi E, Sabry N, Sedrak A, Khowailed A, Loza N. Sociodemographic Indicators for Substance Use and Abuse in Egypt. J Addiction Prevention. 2016; 4(1): 8.

[21] Haddad, L., Shotar, A., Umlauf, M., \& Al-Zyoud, S. Knowledge of substance abuse among high school students in Jordan. Journal of Transcultural Nursing; (2010), 21: 143-150. Alcohol and cannabis use: Final results of the climate schools alcohol and cannabis course. Addiction, Accepted 21st October 2009.

[22] Aliaa M. El-Afandy and Dr. Eman M. Hassan. Effect of Nursing Intervention for Secondary School Students about Substance Abuse Prevention in Sammanoud City, Gharbia Governorate, Egypt. IOSR Journal of Nursing and Health Science (IOSR-JNHS). e-ISSN: 2320-1959.p- ISSN: 2320-1940 Volume 6, Issue 1 Ver. II (Jan. - Feb. 2017), PP 01-13.

[23] Amanda Redvers. Theory of Addiction. The British Journal of Psychiatry Aug 2007, 191 (3) 273-274.
[24] Gibson, World News With Charles (May 5, 2010). "Egypt's Pot Problem? A Marijuana Shortage”. ABC News. Retrieved July 29, 2015.

[25] Julie Ann Pooley, M. Psych, Moira O’Connor, Ph.D. Environmental Education and Attitudes. Emotions and Beliefs are What is Needed. environment and behavior journal; First Published September 1, 2000, Vol 32, Issue 5.

[26] Beck, J. S. (2011). Cognitive behavior therapy: Basics and beyond (2nd ed.). New York, NY:Guilford Press.

[27] Mustafa kayihan erbaş1, mehmet güçlü2, erdal zorba2. Effects of parental attitudes on physical education course attitudes among adolescents. Physical education and sport vol. 11, no 3, 2013, pp. 209-219.

[28] Cuijper GM. Effective ingredients of school-based drug prevention programs: a systematic review. Addict Behav 2002; 27(6): 1009-1023.

[29] Discrepancies in Adolescents' and Mothers' Perceptions of the Family and Mothers' Psychological Symptomatology.

[30] Christine McCauley Ohannessian1 • Robert Laird2 • Andres De Los Reyes3 Received: 27 January 2016 / Accepted: 23 March 2016 Springer Science+Business Media New York 2016.

[31] Shek, D. T. L. (2007). A longitudinal study of perceived differences in parental control and parent-child relational qualities in Chinese adolescents in Hong Kong. Journal of Adolescent Research, 22(2), 156-188. 